\title{
CAPACITY COORDINATION MECHANISM FOR SUPPLY CHAIN UNDER SUPPLY-DEMAND UNCERTAINTY
}

\author{
Li, M.; Wu, G.-D.* \& Lai, X. D. \\ Jiangxi University of Finance \& Economics, Nanchang, 330013, China \\ E-Mail: gd198410@126.com ( ${ }^{*}$ Corresponding author)
}

\begin{abstract}
In consideration of the supply-demand uncertainty, this paper mainly discussed the capacity coordination of product service supply chain. Facing supply uncertainty, it built a subcontractor-supplier coordination model based on penalty contracts. It was found that if the subcontractor takes punitive measures, the benefits caused by the increased subcontract demand can offset the supplier's shortage loss. As to the demand uncertainty, we constructed a coordination model consisting of subcontractors and integrated service suppliers based on the benefit sharing contract. The results found that the integrated service suppliers' order quantity and the expected joined revenue of subcontractors and integrated service suppliers will increase. Besides, considering suppliers' shared capability information, we built a product service supply chain coordination model based on penalty-benefit sharing joined contracts. The results showed that the joined contracts can decrease the uncertainty of capacity supply and soften the impact of demand uncertainty, thus raising the whole benefits of the product service supply chain, and ensuring the benefit increase of all related enterprises.

(Received, processed and accepted by the Chinese Representative Office.)
\end{abstract}

Key Words: Capacity Coordination, Supply Uncertainty, Demand Uncertainty, Contract Coordination

\section{INTRODUCTION}

The product service supply chain provides clients with the product service system with comprehensiveness, stable quality and reasonable price. The fluctuation periods of clients' demand for different value modules in the product service system. Clients' demand fluctuation decides the capacity supply of the product service supply chain. Though the manufacturing resources and service capacity of all membership enterprises are left unused during trough the periods, they have to invest the resources according maximum loads. Since the uncertainty, individuation, diversification and dynamics of market demand, the uncertainty tends to increase for the demand from downstream membership enterprises or clients satisfied by the upstream membership enterprises of the product service supply chain, which makes it hard for upstream membership enterprises to definitely prepare the capacity scale that can cover the demand. Therefore, compared with the traditional product supply chain and service supply chain, the upstream capacity supply uncertainty of the product service supply chain has been increased to great extent. The capacity supply uncertainty has impacted on the production and service of downstream membership enterprises, and finally causes the satisfaction of client demand. Up to now, literatures on the capacity coordination of supply chains, no matter it is product supply chains or service supply chains, are seldom to consider the uncertainty of supply and demand simultaneously. Therefore, this paper aims at exploring the capacity coordination mechanism of the product service system under supply-demand uncertainty and drawing up management strategies for the product service supply chain coordination. 


\section{LITERATURE REVIEW}

\subsection{Literature review for supply chain coordination}

Supply chain coordination is one of the key issues of supply chain management study. Essentially, supply chain coordination is the coordination of different decision functions (e.g. manufacturer-distributor function) [1]. Arshinder et al. (2008), by literature review, summarized the major levels of the product supply chain coordination, there are including procurement-manufacture, manufacture-stock, stock-distribution and manufacture-distribution, the common strategies are including supply chain contracts, information technologies, information sharing and joined decision making [2]. Cachon (2002) completely studied different kinds of supply chain contracts, and found that benefit sharing contracts and buy-back contracts are essentially the same [3]. Chen et al. (2008), taking retail price as the decision variable, commented that the product's residual value is related to its production cost, and built a coordination model based on benefit sharing contracts [4]. After that, Chen and Guo (2010) constructed a coordination model consisting of single supplier and single retailer based on benefit sharing contracts with assumption that the unit product production cost and the cost of marketing increases and the market demand function is in multiplicative form [5]. All the researches above were carried out from the perspective of price factor. However, with the importance of service becoming increasingly remarkable, some non-price factors (quality, time, information and client preference) came into the study field of supply chain coordination [6].

Kraiselburd et al. (2004) studied the supply chain coordination problem in which one retailer sells replaceable products from two suppliers at the same time and the suppliers' levels of promotion effort have direct effect on its product demand [7]. Liu and Tang (2005) studied the service level decision making under varying lead time. As for clients' behaviour choices under shortage, he introduced client tolerance degree, estimated the clients' loss according to their waiting time, and analysed the impact of different lead time on service level decision making [8]. Diao et al. (2008) considered the influence of the uncertainty of consumers' demand preference on the retailer's choices about pricing strategy [9]. By using of the Hotelling Model with Stackelberg game equilibrium, he introduced the uncertainty of consumers' demand preference and studied its influence on the retailer's competition strategy. Shen et al. (2010), within the constraints of certain service level, considered clients' strategic returning behaviour and built coordination models based on ordinary buy-back contracts, discriminatory pricing buy-back contracts and sales rebate contracts, respectively [10].

Therefore, Shen et al. (2009), seeing service as the manufacturers' long term benefit source, studied the product-supplementary service as the manufacturer's benefit increase polar [11]. Game analysis was carried out for the two-stage oligarch competition market where both product sales and product-supplementary service exist. Shen and Xiong (2009) also explored the influence of manufacturers' promise behaviour under information asymmetry on the market structure of product-supplementary service and the manufacturer-retailer game equilibrium [12]. The research in service supply chain coordination mainly lies in logistics service supply chain. For example, Liu et al. (2008) took the two-stage supply chain including single functional type service supplier and single logistics service integrator as study objective [13]. Cui and Liu (2009) pointed out that the logistics service supply chain as a kind of capacity chain is different from the product supply chain and its coordination can only be achieved by adjusting the logistics service capability [14]. He proposed a kind of coordination mechanism based on option contracts so as to study the order and investment decision making of the service capacity of the logistics service integrator and the distributor. Lu et al. (2010) pointed out that the coordination of telecommunication service supply chain is different from 
that of the product supply chain because the former does not have stock of tangible products and all sales income is owned by telecom operators, on the basis of which he built a coordination model based on benefit sharing contracts [15].

It can be seen from the above literature review that in the field of supply chain coordination, the product supply chain has been studied relatively completely, focusing on the decision making of the price and amount of tangible products. Some literatures also considered service capacity factors as subsidiary to tangible products and built the product service supply chain benefit model and its coordination mechanism [16]. The research of the service supply chain converges on logistics and telecom industry.

\subsection{Literature review for service supply chain capacity management}

The management problem of the service supply chain capacity comes of the peculiarity of service. Up to now, the study of service supply chain capacity management focuses on logistics service supply chain. For instance, Tian et al. (2008) predicted the consumer demand by estimating the price elasticity parameter and made service capacity distribution scheme, by which the specialization and flexibility of the service capacity were enhanced [17]. After that, Lee and $\mathrm{Ng}$ (2009) studied the influence of sales price sensitiveness on capacity distribution and the optimal price in capacity advance booking [18].

Ma (2009) thought that the logistics service supply chain is actually based on capacity cooperation. With logistics integrators being the core, it integrates logistics resources of all membership enterprises on the chain and members realize relationship synergy and multi-side win based on their capacity division and cooperation [19]. Gao et al. (2009), based on the resources fundamental theory, put forward that the logistics service supply chain is a chain of logistics capacity-adding [20]. In that chain, the integration of every single logistics capacity makes the basis of the core logistics capacity, thus achieving win for all node enterprises on the whole logistics service supply chain. Li and Ma (2009) thought that the logistics capacity flexibility of node enterprises on the supply chain is the key that determines whether the distributed supply chain can respond to consumer demand quickly or not [21]. Ma and Meng (2005) thought that logistics capacity, consisting of tangible elements, intangible elements and synthesized elements, is the objective capacity formed on the basis of the physical structure of logistics systems and the reflection of the manager's organizational and managerial abilities in the logistics operation process [22]. Liu et al. (2008) studied how the logistics service integrator will distribute order tasks when facing several function type service suppliers under demand uncertainty, and come up with the task distribution model based on different logistics capacity [23]. As for the capability of logistics service integrator and the supplier on the problem of procurement and investment coordination, Wang and Ma (2011) constructed the decision model for the logistics service integrator and the supplier based on Stackelberg game, then proposed the compensation and coordination mechanism for capacity procurement cost based on benefit sharing [24]. Zhu et al. (2012) put forward with a coordination model based on quantity cooperation alliance to solve the coordination problem of a three-echelon logistics service supply chain that consists of the logistics service integrator, the functional logistics service supplier and the logistics capacity subcontractor [25].

\section{PROBLEM DESCRIPTION AND BASIC ASSUMPTIONS}

(1) For each value module of the product service system, all membership enterprises on the product service supply chain coordinate their capacity in order to satisfy the consumer demand for that module. 
(2) A supply chain that consists of one supplier with uncertain capacity, one capacity-limited subcontractor and the integrated service supplier offers product service system for the market (Fig. 1).

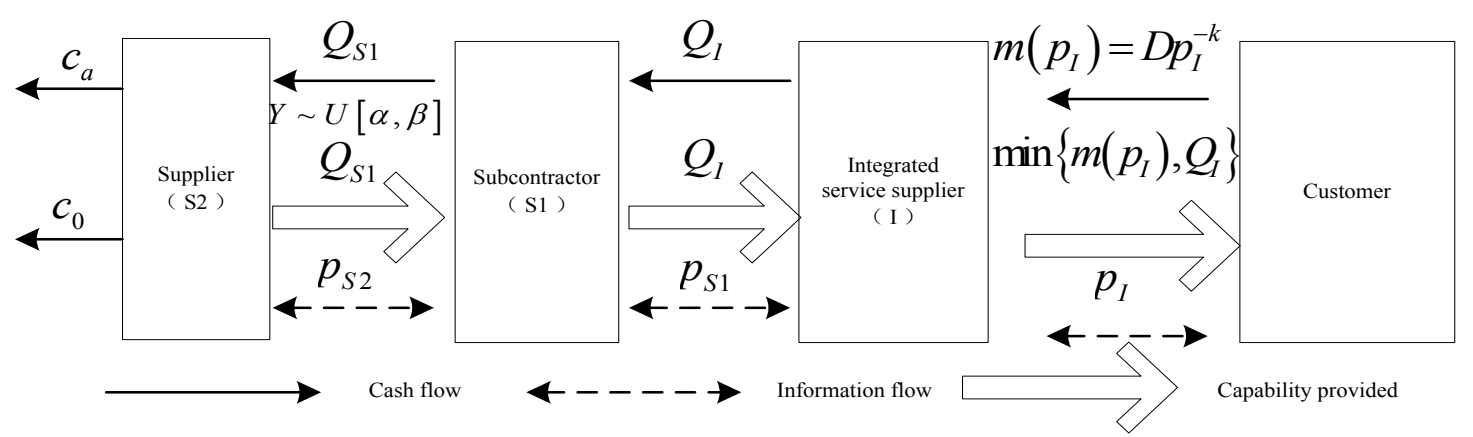

Figure 1: Structure flow of product service supply chain.

(3) The supplier's normal capacity is $v$, that is able to satisfy several clients' demand (including intermediate clients'). The supplier's normal capacity is opened to all its clients whose capacity demand is randomly distributed and interdependent. We use the random variable $Y \sim U[\alpha, \beta](0 \leq \alpha \leq \beta \leq 1)$, of which the density function and distribution function are $f_{Y}(y)$ and $F_{Y}(y)$ respectively, to describe the uncertainty of the capacity distribution. To minimize capacity shortage loss, the supplier considers preparing extra capacity $\eta$ to fulfill the subcontractor's demand. The extra capacity has priority over normal capacity and is a decision variable. The unit cost of normal capacity and extra capacity is $c_{0}$ and $c_{\mathrm{a}}$. The sales price of unit capacity is $p_{S 2}$ while the cost of unit capacity unused is $h$. We have $c_{0}<c_{\mathrm{a}}<p_{S 2}$.

(4) The subcontractor has fixed capacity of $\mu$, the unit cost of which is $c_{S 1}$. The subcontractor's purchase amount from the supplier is $Q_{S 1}$. The procurement amount of the integrated service supplier is $Q_{I}$, that is price-sensitive, i.e. $Q_{I}=Q\left(p_{S 1}\right)$, which is the decreasing concave function of the subcontractor's supplying price $p_{S 1}\left(Q\left(p_{S 1}\right)<0\right.$ and $\left.Q^{\prime \prime}\left(p_{S 1}\right)>0\right)$. The subcontractor's self-making cost is lower than that of subcontracting, i.e. $c_{S 1}<p_{S 2}$.

(5) The integrated service supplier and subcontractor do not share information and the subcontractor has to estimate the order quantity of the integrated service supplier $\left(Q\left(p_{S 1}\right)\right)$. The integrated service supplier faces random market demand $X$, whose price is sensitive to the market with the density function of $f_{X}(x)$. The expected market demand is $m\left(p_{I}\right)=D p_{I}^{-k}$, where $p_{I}$ is the unit sales price made by the integrated service supplier, $D>0$ is a constant, and $k>1$ is the fixed price elasticity coefficient. The objective of the integrated service supplier is to maximize the expected profit by determining sales price $p_{I}$ and order quantity $Q_{I}$ simultaneously. Herein, the residual value is assumed to be zero.

\subsection{The decision behaviour analysis of the product service supply chain under the scattered circumstance}

Under the scattered circumstance, the integrated service supplier, the subcontractor and the supplier all make decisions to maximize their benefits. Then, we have the benefit function of the supplier $\left(\pi_{S 2}(\eta)\right)$ as eq. (1) shows.

$$
\pi_{S 2}(\eta)=p_{S 2} \min \left\{\eta+v Y, Q_{S 1}\right\}-c_{a} \eta-c_{0} \min \left\{v Y, Q_{S 1}-\eta\right\}-h \max \left\{\eta+v Y-Q_{S 1}, 0\right\}
$$

The supplier's expected benefit $E\left[\pi_{S 2}(\eta)\right]$ is:

$$
\begin{aligned}
& E\left[\pi_{S 2}(\eta)\right]=\int_{\alpha}^{\left(Q_{S 1}-\eta\right) / v}\left(p_{S 2}(\eta+v y)-c_{0} v y-c_{a} \eta\right) f_{Y}(y) d y \\
& +\int_{\left(Q_{S 1}-\eta\right) / v}^{\beta}\left(p_{S 2} Q_{S 1}-c_{0}\left(Q_{S 1}-\eta\right)-c_{a} \eta-h\left(\eta+v y-Q_{S 1}\right)\right) f_{Y}(y) d y
\end{aligned}
$$


The subcontractor's benefit function $\pi_{S 1}\left(p_{S 1}\right)$ is:

$$
\pi_{S 1}\left(p_{S 1}\right)=p_{S 1} Q_{I}-c_{S 1} \min \left\{Q_{I}, \mu\right\}-p_{S 2} \max \left\{Q_{I}-\mu, 0\right\}
$$

Because of the supplier's uncertain capacity supply and extra capacity decision, the subcontractor's subcontracting quantity cannot be satisfied completely. So the benefit of the subcontractor is:

$$
p_{S 1} \min \left\{Q_{I}, \mu+\eta^{*}+v Y\right\}-c_{S 1} \min \left\{Q_{I}, \mu\right\}-p_{S 2} \min \left\{\max \left\{Q_{I}-\mu, 0\right\}, \eta^{*}+v Y\right\}
$$

Though the supplier's extra capacity $\eta^{*}$ is given, it cannot be substituted to eq. (4) since the supplier and the subcontractor do not share information.

The subcontractor aims at maximizing its expected benefit $\left(E\left[\pi_{S 1}\left(p_{S 1}\right)\right]\right)$ by deciding sales price $p_{S 1}$. Based on the above assumptions, we can get the solution for $d E\left[\pi_{S 1}\left(p_{S 1}\right)\right] / d p_{S 1}=0$, i.e. the subcontractor's optimal sales price. However, due to the error in the integrated service supplier's order quantity and the supplier's capacity uncertainty, the subcontractor's expected benefit may be lower than $E\left[\pi_{S 1}\left(p_{S 1}{ }^{*}\right)\right]$.

The integrated service supplier's benefit function $\pi_{I}\left(p_{I}, Q_{I}\right)$ and its expected benefit $E\left[\pi_{I}\left(p_{I}, Q_{I}\right)\right]$ are shown in eqs. (5) and (6), respectively.

$$
\begin{gathered}
\pi_{I}\left(p_{I}, Q_{I}\right)=p_{I} \min \left\{x, Q_{I}\right\}-p_{S 1} Q_{I} \\
E\left[\pi_{I}\left(p_{I}, Q_{I}\right)\right]=\int_{0}^{Q_{I}}\left(p_{I} x-p_{S 1} Q_{I}\right) f_{X}\left(x \mid p_{I}\right) d x+\int_{Q_{I}}^{\infty}\left(\left(p_{I}-p_{S 1}\right) Q_{I}\right) f_{X}\left(x \mid p_{I}\right) d x
\end{gathered}
$$

If the integrated service supplier has certain decision risk preference, $z=Q_{I} / m\left(p_{I}\right)$ is used to quantify its risk attitude level [26]. The smaller $z$ is, the more conservative the integrated service supplier is (i.e. the risk aversion is higher). Substitute $Q_{I}=z m\left(p_{I}\right)$ into eq. (6), and $E\left[\pi_{I}\left(p_{I}, Q_{I}\right)\right]$ will become a function of one variable as eq. (7) shows.

$$
E\left[\pi_{I}\left(p_{I}, Q_{I}\right)\right]=\int_{0}^{z m\left(p_{I}\right)}\left(p_{I} x-p_{S 1} z m\left(p_{I}\right)\right) f_{X}\left(x \mid p_{I}\right) d x+\int_{z m\left(p_{I}\right)}^{\infty}\left(\left(p_{I}-p_{S 1}\right) z m\left(p_{I}\right)\right) f_{X}\left(x \mid p_{I}\right) d x
$$

According to the subcontractor's sales price $p_{S 1}{ }^{*}$, the integrated service supplier determines sales price $p_{I}$ and order quantity $Q_{I}$ to maximize its expected profit $E\left[\pi_{I}\left(p_{I}, Q_{I}\right)\right]$.

Let $t=x / m\left(p_{I}\right)$ and $\varepsilon=\int_{0}^{z}\left(1-F_{T}(t)\right) d t$, the integrated service supplier's expected benefit $E\left[\pi_{I}\left(p_{I}, Q_{I}\right)\right]$ changes to:

$$
\begin{aligned}
& E\left[\pi_{I}\left(p_{I}, Q_{I}\right)\right]=p_{I} \int_{0}^{z m\left(p_{I}\right)}\left(1-F_{X}\left(x \mid p_{I}\right)\right) d x-p_{S 1} z m\left(p_{I}\right) \\
& =m\left(p_{I}\right)\left(p_{I} \int_{0}^{z}\left(1-F_{T}(t)\right) d t-p_{S 1} z\right)=D\left(p_{I}\right)^{-k}\left(p_{I} \varepsilon-p_{S 1} z\right)
\end{aligned}
$$

Solve the first-order derivative of eq. (8) to $p_{I}$, and we will get:

$$
\frac{d E\left[\pi_{I}\left(p_{I}, Q_{I}\right)\right]}{d p_{I}}=D\left(p_{I}\right)^{-1-k}\left((1-k) p_{I} \varepsilon+k p_{S 1} z\right)
$$

Let the above expression equal to zero, and we will get $p_{I}^{*}=\left(k p_{S 1} z\right) /((k-1) \varepsilon)$.

When the integrated service supplier's order quantity exceeds the subcontractor's capacity, the subcontractor will subcontract order quantity of $Q_{S 1}{ }^{*}=Q_{I}{ }^{*}-\mu$ to the supplier. However, the supplier's uncertain capacity makes it possible that the subcontractor cannot satisfy the integrated service supplier's order quantity $Q_{I}{ }^{*}$, and causes the expected benefit of the integrated service supplier is possibly below $E\left[\pi_{I}\left(p_{I}{ }^{*}, Q_{I}{ }^{*}\right)\right]$. According to the assumptions above, after accepting the subcontracting quantity $Q_{S 1}{ }^{*}=Q_{I}{ }^{*}-\mu$, the supplier will determine the optimal extra capacity $\eta^{*}$ so as to maximize its expected benefit $E\left[\pi_{S 2}\left(\eta^{*}\right)\right]$. 


\subsection{Decision behaviour analysis of supply chain under coordinated circumstance}

3.2.1 The supplier-subcontractor coordination model

The supplier, if not satisfying the subcontractor's subcontracting demand, will suffer shortage penalty, with unit shortage cost $c_{s}$. The coordination mechanism design, to some great extent, depends on the positions of the supplier and the subcontractor. Herein we assume the subcontractor holds the position of leadership and makes penalty measures. When penalty measures are considered, the supplier's benefit function $\pi_{S 2}^{I}(\eta)$ becomes:

$$
\begin{aligned}
& \pi_{S 2}^{I}(\eta)=p_{S 2} \min \left\{\eta+v Y, Q_{S 1}\right\}-c_{a} \eta-c_{0} \min \left\{v Y, Q_{S 1}-\eta\right\}-h \max \left\{\eta+v Y-Q_{S 1}, 0\right\} \\
& -c_{s} \max \left\{Q_{S 1}-\eta-v Y, 0\right\}
\end{aligned}
$$

The supplier's expected benefit $E\left[\pi_{S 2}^{I}(\eta)\right]$ becomes:

$$
\begin{aligned}
& E\left[\pi_{S 2}^{I}(\eta)\right]=\int_{\alpha}^{\left(Q_{S 1}-\eta\right) / v}\left(p_{S 2}(\eta+y v)-c_{0} v y-c_{a} \eta\right) f_{Y}(y) d y+ \\
& \int_{\left(Q_{S 1}-\eta\right) / v}^{\beta}\left(p_{S 2} Q_{S 1}-c_{0}\left(Q_{S 1}-\eta\right)-c_{a} \eta-h\left(\eta+v y-Q_{S 1}\right)\right) f_{Y}(y) d y-c_{s} \int_{\alpha}^{\left(Q_{S 1}-\eta\right) / v}\left(Q_{S 1}-\eta-v y\right) f_{Y}(y) d y
\end{aligned}
$$

Under the coordinated circumstance, the supplier targets at deciding the optimal $\eta$ so as to maximize its expected benefit $E\left[\pi_{S 2}^{I}(\eta)\right]$. Since $E\left[\pi_{S 2}^{I}(\eta)\right]$ is the concave function of $\eta$, the optimal $\eta$ can be got by solving $d E\left[\pi_{S 2}^{I}(\eta)\right] / d \eta=0$.

$$
\eta^{I}=\left\{\begin{array}{cl}
Q_{S 1}-v \frac{p_{S 2} \alpha+c_{a}(\beta-\alpha)+\left(h-c_{0}\right) \beta+c_{s} \alpha}{p_{S 2}+h-c_{0}+c_{s}} & \text { when } Q_{S 1}>0 \text { and } \eta^{I}>0 \\
0 & \text { others }
\end{array}\right.
$$

Theorem 1 The supplier's expected benefit $E\left[\pi_{S 2}^{I}(\eta)\right]$ is the concave function of extra capacity $\eta$ and the unique optimal solution exists.

The supplier's optimal expected profit $E\left[\pi_{S 2}^{I}\left(\eta^{I}\right)\right]$ is shown in eq. (12) where $\theta=\left(p_{S 2} \alpha+c_{a}(\beta-\alpha)+\left(h-c_{0}\right) \beta+c_{s} \alpha\right) /\left(p_{S 2}+h-c_{0}+c_{s}\right):$

$$
\begin{aligned}
E\left[\pi_{S 2}^{I}\left(\eta^{I}\right)\right]= & \frac{1}{2(\beta-\alpha)}\left\{2 Q_{S 1}\left(p_{S 2}-c_{a}\right)(\beta-\alpha)-p_{0} v(\theta-\alpha)^{2}+\right. \\
& \left.v\left[2 c_{a}(\beta-\alpha) \theta+2 c_{0}\left(\theta^{2}-(\alpha+\beta) \theta+\alpha^{2}\right)-h(\beta-\theta)^{2}-c_{s}(\theta-\alpha)^{2}\right]\right\}
\end{aligned}
$$

According to eq. (12), given the same $Q_{S 1}$, when unit shortage penalty cost tends to 0 , the expression of $\eta^{I}$ is the same with that of $\eta^{*}$, i.e. the supplier's optimal expected benefit equals to that under the scattered circumstance $\left(E\left[\pi_{S 2}^{I}\left(\eta^{I}\right)\right]=E\left[\pi_{S 2}\left(\eta^{*}\right)\right]\right)$. From the perspective of the subcontractor, since $d \eta^{I} / d c_{s}=v\left(h+c_{a}-c_{0}\right)(\beta-\alpha) /\left(p_{S 2}+h-c_{0}+c_{s}\right)^{2}>0$, given the subcontracting quantity of $Q_{S 1}$, the increase of unit shortage penalty cost $\left(c_{s}\right)$ will raise the possibility of satisfying $Q_{S 1}$, namely $1-F_{Y}\left(\left(Q_{S 1}-\eta^{I}\right) / v\right)$, and thus reduce the uncertainty of capacity supply.

Under the coordinated circumstance, the subcontractor's benefit function $\pi_{S 1}^{I}\left(p_{S 1}\right)$ is:

$$
\begin{aligned}
\pi_{S 1}^{I}\left(p_{S 1}\right)= & p_{S 1} \min \left\{Q_{I}, \mu+\eta^{I}+v Y\right\}-c_{S 1} \min \left\{Q_{I}, \mu\right\}- \\
& p_{S 2} \min \left\{\max \left\{Q_{I}-\mu, 0\right\}, \eta^{I}+v Y\right\}+c_{s} \max \left\{Q_{I}-\mu-\eta^{I}-v Y, 0\right\}
\end{aligned}
$$

Since $\eta^{I} \geq \eta^{*}, \pi_{S 1}^{I}\left(p_{S 1}\right)$ is greater or equal to the benefit under the scattered circumstance $\left(\pi_{S 1}\left(p_{S 1}\right)\right)$. Then we have $E\left[\pi_{S 1}^{I}\left(p_{S 1}\right)\right] \geq E\left[\pi_{S 1}\left(p_{S 1}\right)\right]$.

The subcontractor's expected benefit $E\left[\pi_{S 1}^{I}\left(p_{S 1}\right)\right]$ is shown in eq. (14) where $Q_{I}=Q\left(p_{S 1}\right)$ :

$$
\begin{aligned}
& E\left[\pi_{S 1}^{I}\left(p_{S 1}\right)\right]=\int_{\alpha}^{\left(Q_{I}-\mu-\eta^{I}\right) / v}\left(p_{S 1}\left(\eta^{I}+v y+\mu\right)-c_{S 1} \mu-p_{S 2}\left(\eta^{I}+v y\right)\right) f_{Y}(y) d y \\
& +\int_{\left(Q_{I}-\mu-\eta^{I}\right) / v}^{\beta}\left(p_{S 1} Q_{I}-c_{S 1} \mu-p_{S 2}\left(Q_{I}-\mu\right)\right) f_{Y}(y) d y+c_{s} \int_{\alpha}^{\left(Q_{I}-\mu-\eta^{I}\right) / v}\left(Q_{I}-\mu-\eta^{I}-v y\right) f_{Y}(y) d y
\end{aligned}
$$


Let $d E\left[\pi_{S 1}^{I}\left(p_{S 1}\right)\right] / d p_{S 1}=0$, and we will find that the optimal solution of the unit sales price maximizing the subcontractor's expected benefit satisfies:

$$
p_{S 1}^{I}=p_{S 2}-\left(Q_{I}\left(p_{S 1}^{I}\right)-\frac{v(\theta-\alpha)^{2}}{2(\beta-\alpha)}\right) / Q_{I}^{\prime}\left(p_{S 1}^{I}\right)
$$

where $\theta=\left(p_{0} \alpha+w(\beta-\alpha)+\left(h-c_{0}\right) \beta+c_{s} \alpha\right) /\left(p_{0}+h-c_{0}+c_{s}\right)$. From all above, it is clear that when $c_{s}=0$, the subcontractor's expected benefit $E\left[\pi_{S 1}^{I}\left(p_{S 1}\right)\right]$ is greater or equal to that under the scattered circumstance $\left(E\left[\pi_{S 1}\left(p_{S 1}{ }^{*}\right)\right]\right)$. Besides, on the basis of the information sharing from the supplier on its normal capacity and extra capacity, the subcontractor can make more reasonable decisions by adjusting $Q_{S 1}$.

3.2.2 The subcontractor and integrated service supplier coordination model

Within benefit sharing contracts, the subcontractor sells to the integrated service supplier at the price $p_{S 1}^{I I}$ below the unit average cost, and the integrated service supplier reduces retail price in order to stimulate more demand. Apparently, the subcontractor's benefit becomes negative. To achieve coordination, the integrated service supplier will share benefits with the subcontractor by returning part of its benefit, namely $\left(1-\xi^{I}\right)$, to the subcontractor. The parameter of the benefit sharing contract $\left(\xi^{I}\right)$ is decided by the coordination between the subcontractor and the integrated service supplier. Within the benefit sharing contract, integrated service supplier's benefit $\pi_{I}^{I I}\left(p_{I}, Q_{I}\right)$ is:

$$
\pi_{I}^{I I}\left(p_{I}, Q_{I}\right)=\xi^{I} p_{I} \min \left\{x, Q_{I}\right\}-p_{S 1}^{I I} Q_{I}
$$

The supplier's benefit $\pi_{S 1}^{I I}\left(p^{I I}{ }_{S 1}\right)$ is:

$$
\pi_{S 1}^{I I}\left(p_{S 1}^{I I}\right)=\left(1-\xi^{I}\right) p_{I} \min \left\{x, Q_{I}\right\}+p_{S 1}^{I I} Q_{I}-c_{S 1} \min \left\{Q_{I}, \mu\right\}-p_{S 2} \max \left\{Q_{I}-\mu, 0\right\}
$$

When the subcontractor coordinates with the integrated service supplier, but not with the supplier, the joined benefit of the subcontractor and the integrated service supplier $\left(\pi^{I I}{ }_{S 1 I}\left(p_{I}, Q_{I}\right)\right)$ is shown in eq. (17):

$$
\pi_{S 1 I}^{I I}\left(p_{I}, Q_{I}\right)=p_{I} \min \left\{x, Q_{I}\right\}-c_{S 1} \min \left\{Q_{I}, \mu\right\}-p_{S 2} \max \left\{Q_{I}-\mu, 0\right\}
$$

If $Q_{I} \geq \mu$, the expected joined benefit of the subcontractor and the integrated service supplier $\left(E\left[\pi^{I I}{ }_{S 1 I}\left(p_{I}, Q_{I}\right)\right]\right)$ is shown in eq. (18):

$$
\begin{aligned}
E\left[\pi_{S 1 I}^{I I}\left(p_{I}, Q_{I}\right)\right] & =\int_{0}^{Q_{I}}\left(p_{I} x-c_{S 1} \mu-p_{S 2}\left(Q_{I}-\mu\right)\right) f_{X}\left(x \mid p_{I}\right) d x \\
& +\int_{Q I}^{\infty}\left(p_{I} Q_{I}-c_{S 1} \mu-p_{S 2}\left(Q_{I}-\mu\right)\right) f_{X}\left(x \mid p_{I}\right) d x
\end{aligned}
$$

In the coordination model based on benefit sharing contracts, the integrated service supplier's optimal decision will be the one satisfying that the sum of the expected benefits of the subcontractor and the integrated service supplier equals the expected joined benefit of the subcontractor and the integrated service supplier, i.e. satisfying:

$$
E\left[\pi_{I}^{I I}\left(p_{I}, Q_{I}\right)\right]+E\left[\pi_{S 1}^{I I}\left(p_{S 1}^{I I}\right)\right]=E\left[\pi_{S 1 I}^{I I}\left(p_{I}, Q_{I}\right)\right] .
$$

So we get $p^{I I}{ }_{S 1}=\xi^{I} p_{S 2}$, then we get the integrated service supplier's expected benefit $E\left[\pi^{I I}\left(p_{I}, Q_{I}\right)\right]$ as eq. (19) shows.

$$
E\left[\pi_{I}^{I I}\left(p_{I}, Q_{I}\right)\right]=\xi^{I} E\left[\pi_{S 1 I}^{I I}\left(p_{I}, Q_{I}\right)\right]
$$

The subcontractor's expected benefit $E\left[\pi_{S 1}^{I I}\left(p_{S 1}^{I I}\right)\right]$ is:

$$
E\left[\pi_{S 1}^{I I}\left(p_{S 1}^{I I}\right)\right]=\left(1-\xi^{I}\right) E\left[\pi_{S 1 I}^{I I}\left(p_{I}, Q_{I}\right)\right]
$$

Since $E\left[\pi^{I I}{ }_{S 1 I}\left(p_{I}, Q_{I}\right)\right]$ is similar with eq. (6), we substitute $Q_{I}=z D\left(p_{I}\right)^{-k}$ into eq. (18) and transform $E\left[\pi_{S 1 I}^{I I}\left(p_{I}, Q_{I}\right)\right]$ into a function of one variable $\left(E\left[\pi_{S 1 I}^{I I}\left(p_{I}\right)\right]\right)$.

In the coordination model between the subcontractor and the integrated service supplier, it is expected that the optimal expected benefits of the subcontractor and the integrated 
service supplier should be greater those under the scattered circumstance, respectively, i.e. $E\left[\pi^{I I}{ }_{S 1}\left(p^{I I}{ }_{S 1}\right)\right]>E\left[\pi_{S 1}\left(p_{S 1}{ }^{*}\right)\right]$ and $E\left[\pi^{I I}\left(p_{I}^{I I}, Q_{I}^{I I}\right)\right]>E\left[\pi_{I}\left(p_{I}{ }^{*}, Q^{*}\right)\right]$ should be true simultaneously.

Substituting eqs. (19) and (20) into the inequalities above respectively, we get the range of $\xi^{I}$ between which the supplier's expected benefit $E\left[\pi^{I I}(\eta)\right]$ is the same as that under the scattered circumstance.

$$
\begin{aligned}
& E\left[\pi_{s 2}^{I I}(\eta)\right]=\int_{\alpha}^{\left(Q_{S 1}-\eta\right) / v}\left(p_{S 2}(\eta+v y)-c_{0} v y-c_{a} \eta\right) f_{Y}(y) d y \\
& +\int_{\left(Q_{S 1}-\eta\right) / v}^{\beta}\left(p_{S 2} Q_{S 1}-c_{0}\left(Q_{S 1}-\eta\right)-c_{a} \eta-h\left(\eta+v y-Q_{S 1}\right)\right) f_{Y}(y) d y
\end{aligned}
$$

The supplier's decision about its extra capacity $\eta^{I I}$ is as following:

$$
\eta^{I I}=\left\{\begin{array}{cc}
Q_{S 1}-v \frac{p_{S 2} \alpha+c_{a}(\beta-\alpha)+\left(h-c_{0}\right) \beta}{p_{S 2}+h-c_{0}} & \text { when } Q_{S 1}>0 \text { and } \eta^{I I}>0 \\
0 & \text { others }
\end{array}\right.
$$

3.2.3 The product service supply chain coordination model

In this coordination model, the supplier's expected benefit $E\left[\pi^{I I I}{ }_{S 2}(\eta)\right]$ and the extra capacity decision $\eta^{I I I}$ is $E\left[\pi_{S 2}^{I}(\eta)\right]$ (eq. (10)) and $\eta^{I}$ (eq. (11)). The joined expected benefit of the subcontractor and the integrated service supplier $\left(E\left[\pi^{I I I}{ }_{S 1 I}\left(p_{I}, Q_{I}\right)\right]\right)$ is the sum of the difference between sales revenue and production cost and the supplier's shortage cost.

$$
\begin{aligned}
& \pi_{S 1 I}^{I I I}\left(p_{I}, Q_{I}\right)=p_{I} \min \left\{x, \min \left\{Q_{I}, \mu+\eta^{I I I}+v Y\right\}\right\}-c_{S 1} \min \left\{Q_{I}, \mu\right\} \\
& -p_{S 2} \min \left\{\max \left\{Q_{I}-\mu, 0\right\}, \eta^{I I I}+v Y\right\}+c_{s} \max \left\{Q_{I}-\mu-\eta^{I I I}-v Y, 0\right\}
\end{aligned}
$$

The supplier's normal capacity information and its extra capacity decision vary in adaption with the subcontracting quantity. When $Q_{I} \geq \mu$, the joined expected benefit of the subcontractor and the integrated service supplier is shown in eq. (23):

$$
\begin{aligned}
E\left[\pi_{S 1 I}^{I I I}\left(p_{I}, Q_{I}\right)\right]= & \int_{\alpha}^{\left(Q_{I}-\mu-\eta^{I I I}\right) / v}\left\{\int_{0}^{\mu+\eta^{I I I}+v y}\left(p_{I} x-c_{S 1} \mu-p_{S 2}\left(\eta^{I I I}+v y\right)\right) f_{X}\left(x \mid p_{I}\right) d x+\right. \\
& \left.\int_{\mu+\eta^{I I}+v y}^{\beta}\left(\left(p_{I}-p_{S 2}\right)\left(\eta^{I I I}+v y\right)-\left(p_{I}-c_{S 1}\right) \mu\right) f_{X}\left(x \mid p_{I}\right) d x\right\} f_{Y}(y) d y \\
& +\int_{\left(Q_{I}-\mu-\eta^{I I I}\right) / v}^{\beta}\left\{\int_{0}^{Q_{1}}\left(p_{I} x-c_{S 1} \mu-p_{S 2}\left(Q_{I}-\mu\right)\right) f_{X}\left(x \mid p_{I}\right) d x\right. \\
& \left.+\int_{Q_{I}}^{\beta}\left(p_{I} Q_{I}-c_{S 1} \mu-p_{S 2}\left(Q_{I}-\mu\right)\right) f_{X}\left(x \mid p_{I}\right) d x\right\} f_{Y}(y) d y \\
& +c_{s} \int_{\alpha}^{\left(Q_{I}-\mu-\eta^{I I I}\right) / v}\left(\left(Q_{I}-\mu\right)-\eta^{I I I}-v y\right) f_{Y}(y) d y
\end{aligned}
$$

Substituting $Q_{I}=z m\left(p_{I}\right)$ and $t=x / m\left(p_{I}\right)$ into eq. (23), and we can transform $E\left[\pi^{I I I}{ }_{S 1 I}\left(p_{I}, Q_{I}\right)\right]$ into the function of one variable $\left(E\left[\pi^{I I I}{ }_{S 1 I}\left(p_{I}\right)\right]\right)$.

$$
\begin{aligned}
E\left[\pi_{S 1 I}^{I I I}\left(p_{I}\right)\right]= & p_{I} \int_{\alpha}^{\theta}\left[m\left(p_{I}\right) \int_{0}^{z-(\theta-y) v / m\left(p_{I}\right)}\left(1-F_{T}(t) d t\right)\right] \frac{1}{\beta-\alpha} d y \\
& +p_{I} \int_{\theta}^{\beta} m\left(p_{I}\right) \varepsilon \frac{1}{\beta-\alpha} d y-c_{S 1} \mu-p_{0}\left[\int_{\alpha}^{\theta}\left(v y+\eta^{I I I}\right) \frac{1}{\beta-\alpha} d y\right. \\
& \left.+\int_{\theta}^{\beta}\left(Q_{I}-\mu\right) \frac{1}{\beta-\alpha} d y\right]+c_{s}\left[\int_{\alpha}^{\theta}\left(Q_{I}-\mu-\alpha v-\eta^{I I I}\right) \frac{1}{\beta-\alpha} d y\right]
\end{aligned}
$$

In eq. (24), $\theta=\left(p_{S 2} \alpha+c_{a}(\beta-\alpha)+\left(h-c_{0}\right) \beta+c_{s} \alpha\right) /\left(p_{S 2}+h-c_{0}+c_{s}\right)$ and $\varepsilon=\int_{0}^{z}\left(1-F_{T}(t)\right) d t$. For the simplicity of calculation, let $r=v / m\left(p_{I}\right)$ where $p_{I}$ is the function of $r$.

$$
p_{I}=(D r / v)^{1 / k}
$$


In eq. (24), replacing $v / m\left(p_{I}\right)$ by $r$, we find that $r$ will result in different $p_{I}^{\#}$ that maximizes benefits given different $r^{\#}$. At the optimal unit sales price $p_{I}^{I I I}$, the ration optimizing $E\left[\pi^{I I I}{ }_{S 1 I}\right.$ $\left.\left(p_{I}\right)\right]$ is $r^{I I I}=v / m\left(p_{I}^{I I I}\right)$. So the sufficient and necessary condition satisfying that $p_{I}^{\#}$ is the optimal sales price $p_{I}^{I I I}$ is that $r^{\#}$ equals to $v / m\left(p_{I}^{\#}\right)$, by which $p_{I}^{\#}$ can be deduced. The Theorem 3 below indicates that $E\left[\pi^{I I I}{ }_{S 1 I}\left(p_{I}\right)\right]$ is the unimodal function of $p_{I}$ given certain $r$.

Theorem 2 The joined expected benefit of the subcontractor and the integrated service supplier $\left(E\left[\pi^{I I I}{ }_{S 1 I}\left(p_{I}, Q_{I}\right)\right]\right)$ is the unimodal function of $p_{I}$ given certain $r$.

In this theorem, given certain $r, p_{I}^{\#}$ is the optimal sales price that maximizing expected benefits. A couple of $\left(p_{I}, r\right)$ can be found that satisfies eq. (25). Since $p_{I}^{\#}$ is the increasing function of $r$ in eq. (25) while $p_{I}^{\#}$ is the decreasing function of $r$ in:

$$
p_{I}^{\#}=\frac{k\left[2 z p_{S 2}(\beta-\alpha)-r\left(p_{S 2}+c_{s}\right)(\theta-\alpha)^{2}\right]}{2(k-1)\left[(\beta-\theta) \varepsilon+\int_{\alpha}^{\theta} \int_{0}^{z-r(\theta-y)}\left(1-F_{T}(t)\right) d t d y\right]},
$$

the two functions cross each other and the unit sales price at the cross point is the optimal sales price $\left(p_{I}^{I I I}\right)$.

When $p_{I}^{I I I}$ is found, the integrated service supplier's order quantity is $Q_{I}^{I I I}=z D\left(p_{I}^{I I I}\right)^{-k}$ and the supplier's extra capacity decision is:

$$
\eta^{I I I}=Q_{S 1}^{I I I}-v\left(p_{S 2} \alpha+c_{a}(\beta-\alpha)+\left(h-c_{0}\right) \beta+c_{s} \alpha\right) /\left(p_{S 2}+h-c_{0}+c_{s}\right) .
$$

From the perspective of the subcontractor, due to:

$d \eta^{I I I} / d c_{s}=v\left(h+c_{a}-c_{0}\right)(\beta-\alpha) /\left(p_{S 2}+h-c_{0}+c_{s}\right)^{2}>0$, if the capacity subcontracting quantity $Q_{S 1}$ is given, the increase of unit shortage cost $\left(c_{S}\right)$ will raise the possibility of satisfying $Q_{S 1}$, thus lowers the capacity supply uncertainty.

In the same way the sales price $\left(p_{S 1}^{I}\right)$ and the parameter of the benefit sharing contract $\left(\xi^{I}\right)$ are solved, in the product service supply chain coordination model, the sales price $\left(p_{S 1} I I\right)$ at which the subcontractor sells to the integrated service supplier has to satisfy $p_{S 1}{ }^{I I I}=\xi^{I I} p_{S 2}$. The subcontractor's expected benefit is $E\left[\pi_{I}^{I I I}\left(p_{I}^{I I I}, Q_{I}^{I I I}\right)\right]=\xi^{I I} E\left[\pi^{I I I}{ }_{S 1 I}\left(p_{I}\right)\right]$ and the integrated service supplier's expected benefit is $E\left[\pi_{I}^{I I I}\left(p_{I}^{I I}, Q_{I}^{I I I}\right)\right]=\xi^{I I} E\left[\pi^{I I I}{ }_{S 1 I}\left(p_{I}\right)\right]$. At this time, the optimal expected benefits of the subcontractor and the integrated service supplier are greater than those under the scattered circumstance, namely, $E\left[\pi_{S 1}{ }^{I I I}\left(p_{S 1}{ }^{I I I}\right)\right]>E\left[\pi_{S 1}\left(p_{S 1}{ }^{*}\right)\right]$ and $E\left[\pi_{I}^{I I I}\left(p_{I}^{I I I}, Q_{I}^{I I I}\right)\right]>E\left[\pi_{I}\left(p_{I}^{*}\right)\right]$ are true simultaneously. Then, we can define the range of the parameter of the benefit sharing contract $\left(\xi^{I I}\right)$.

\section{MODEL SIMULATION}

Here we assume $d=500000$ and $k=2$, then we have $m\left(p_{I}\right)=500000 p_{I}{ }^{-2}$. The supplier's fixed capacity if $v=500$ of which the unit cost is $c_{0}=2$ compared with that of extra capacity $c_{a}=2.5$. The unit sales price is $p_{S 2}=6$ and the unit cost of capacity unused is $h=2.3$. The supplier's supply uncertainty follows distribution of $Y \sim U[0,0.22]$, i.e. $\alpha=0$ and $\beta=0.22$. The subcontractor's capacity is $u=500$ with unit cost $c_{S 1}=3$ and unit shortage cost $c_{s}=1$. The risk attitude of the integrated service supplier is $z=1.5$. $Q\left(p_{S 1}\right)=a p_{S 1}{ }^{-b}$ where $a=3000, b=1.75$.

\subsection{Result analysis under the scattered circumstance}

Since $d E\left[\pi_{S 1}\left(p_{S 1}\right)\right] / d p_{S 1}=0$, we can get the subcontractor's optimal sales price $p_{S 1}{ }^{*}=7$. Substituting $p_{S 1}{ }^{*}=7$ into $Q_{I}{ }^{*}=z D\left(k z p_{S 1}{ }^{*} /(k-1) \varepsilon\right)^{-k}$ and $p_{I}{ }^{*}=\left(k p_{S 1} z\right) /((k-1) \varepsilon)$, we get the integrated service supplier's optimal order quantity ${Q_{I}}^{*}=1027$ and its optimal sales price $p_{I}^{*}=22.1$.

Then we can get the subcontractor's subcontracting quantity $Q_{S 1}{ }^{*}=Q_{I}{ }^{*}-\mu=527$. Substituting $Q_{S 1}{ }^{*}=527$ into $\eta^{*}=Q_{S 1}-v\left(p_{S 2} \alpha+c_{a}(\beta-\alpha)+\left(h-c_{0}\right) \beta\right) /\left(p_{S 2}+h-c_{0}\right)$, we get the supplier's extra capacity decision $\eta^{*}=38$. 
According to all above, the optimal expected benefits of the supplier, the subcontractor and the integrated service supplier $\left(E\left[\pi_{S 2}\left(\eta^{*}\right)\right], E\left[\pi_{S 1}\left(p_{S 1}{ }^{*}\right)\right]\right.$ and $\left.E\left[\pi_{I}\left(p_{I}{ }^{*}, Q^{*}\right)\right]\right)$ can be solved as $1,483,2,418$ and 1,0744 respectively. The uncertainty that the supplier cannot satisfy the subcontractor's demand is: $\operatorname{Pr}\left\{Y<\left(Q_{S 1}-\eta^{*}\right) / v\right\}=F_{Y}\left(\frac{p_{S 2} \alpha+c_{a}(\beta-\alpha)+\left(h-c_{0}\right) \beta}{p_{S 2}+h-c_{0}}\right)=0.44$

\subsection{Result analysis of the subcontractor-supplier coordination model}

According to $d E\left[\pi_{S 1}^{I}\left(p_{S 1}\right)\right] / d p_{S 1}=0$, we can get the subcontractor's optimal sales price $p_{S 1}^{I}=6.85$. Similarly, by $d E\left[\pi_{I}^{I}\left(p_{I}\right)\right] / d p_{I}=0$ we get the integrated service supplier's optimal sales price $p_{I}^{I}=21.6$ and its optimal order quantity $Q_{I}^{I}=1072$.

The subcontractor's subcontracting quantity $Q_{S 1}^{I}=Q_{I}^{I}-\mu=572$. Substituting $Q_{S 1}^{I}=572$ into $\left.\eta^{I}=Q_{S 1}-v\left(p_{S 2} \alpha+c_{a}(\beta-\alpha)+\left(h-c_{0}\right) \beta\right)+c_{s} \alpha\right) /\left(p_{S 2}+h-c_{0}+c_{s}\right)$, we get the supplier's extra capacity decision $\eta^{I}=150$. Then, the optimal expected benefits of the supplier, the subcontractor and the integrated service supplier $\left(E\left[\pi_{S 2}\left(\eta^{I}\right)\right], E\left[\pi_{S 1}\left(p_{S 1}{ }^{I}\right)\right]\right.$ and $\left.E\left[\pi_{I}\left(p_{I}^{I}\right)\right]\right)$ can be solved as 1,552, 2,424 and 10,979. The possibility that the supplier satisfies the subcontractor's demand is $1-F_{Y}\left(\left(Q_{S 1}^{I}-\eta^{I}\right) / v\right)=0.62$. So, the supplier's supply uncertainty has been reduced to some extent compared with the one under the scattered circumstance.

\subsection{Result analysis of the subcontractor and the integrated service supplier coordination model}

In the subcontractor and the integrated service supplier coordination model, the integrated service supplier's optimal order quantity and optimal sales price can be solved as $Q^{I I}{ }_{I}=1397$ and $p_{I}^{I I}=18.9$, respectively. The subcontractor's subcontracting quantity is $Q_{S 1}^{I I}=Q_{I}^{I I}-\mu=897$.

Within the benefit sharing contract, the joined expected benefit of the subcontractor and the integrated service supplier $\left(E\left[\pi^{I I}{ }_{S 1 I}\left(p_{I}^{I I}, Q_{I}^{I I}\right)\right]\right)$ is 15,685 . In the subcontractor and the integrated service supplier coordination model, the optimal expected profits of both the subcontractor and the integrated service supplier should be greater than the ones under the scattered circumstance, we get the range of the parameter of the benefit sharing contract is $0.685<\xi^{I}<0.845$. If the parameter of the benefit sharing contract falls into that range, the subcontractor and the integrated service supplier will accept the coordination contract, but the exact value of the parameter depends on the positions and negotiating ability of both sides.

The parameter of the benefit sharing contract, on the premise of ensuring the coordination between the parameter of the benefit sharing contract, is able to distribute benefits in any way, and thus offers flexibility for the subcontractor and the integrated service supplier who maybe are in the different positions. In the specific range, the expected benefits of the subcontractor and the integrated service supplier vary as Fig. 2 shows.

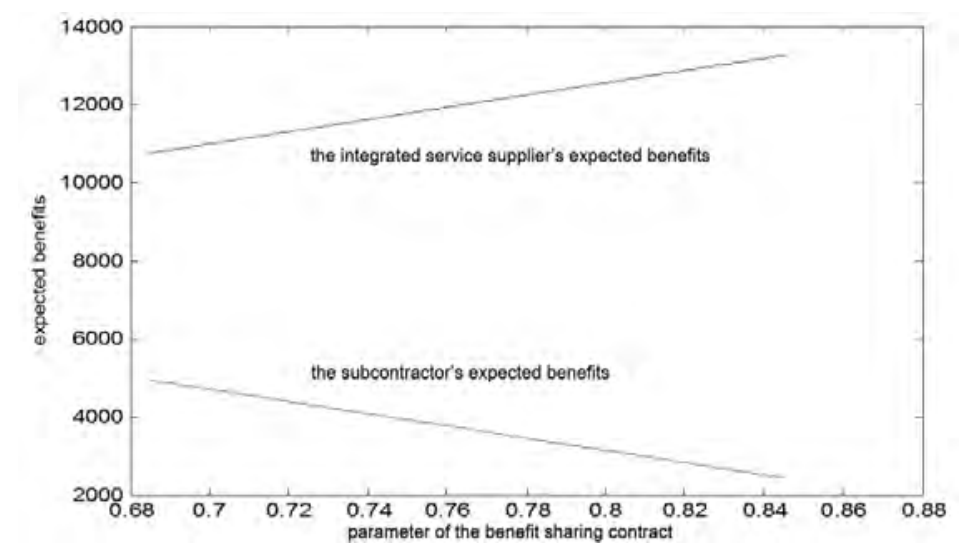

Figure 2: Relationship between revenue sharing and expected profit. 
Substituting $Q_{S 1}^{I I}=897$ into $\left.\eta_{I}^{I I}=Q_{S 1}^{I I}-v\left(p_{S 2} \alpha+c_{a}(\beta-\alpha)+\left(h-c_{0}\right) \beta\right)+c_{s} \alpha\right) /\left(p_{S 2}+h-c_{0}+c_{s}\right)$, we get the supplier's optimal extra service capacity decision $\eta_{I}^{I I}=475$. Further, the supplier's optimal expected profit $\left(E\left[\pi_{0}\left(\eta_{I}^{I I}\right)\right]\right)$ is 2,172 . At this time, the supplier's supply uncertainty is $F_{Y}\left(p_{S 2} \alpha+c_{a}(\beta-\alpha)+\left(h-c_{0}\right) \beta\right) /\left(p_{S 2}+h-c_{0}\right)$, which is the same with the one under the scattered circumstance.

\subsection{Result analysis of the product service supply chain coordination model}

According to $p_{I}^{\#}=\frac{k\left[2 z p_{S 2}(\beta-\alpha)-r\left(p_{S 2}+c_{s}\right)(\theta-\alpha)^{2}\right]}{2(k-1)\left[(\beta-\theta) \varepsilon+\int_{\alpha}^{\theta} \int_{0}^{z-r(\theta-y)}\left(1-F_{T}(t)\right) d t d y\right]}$, we get the integrated service supplier's optimal sales price is $p_{I}^{I I I}=14.75$, and its optimal order quantity is $Q_{I}^{I I I}=1497$. The subcontractor's subcontracting quantity is $Q^{I I I}{ }_{S 1}=Q_{I}^{I I I}-\mu=997$. Substituting $Q^{I I I}{ }_{S 1}=997$ into $\left.\eta^{I I I}=Q^{I I I}{ }_{S 1}-v\left(p_{S 2} \alpha+c_{a}(\beta-\alpha)+\left(h-c_{0}\right) \beta\right)+c_{s} \alpha\right) /\left(p_{S 2}+h-c_{0}+c_{s}\right)$, we get the supplier's extra capacity decision is $\eta_{I}^{I I I}=575$, and its optimal expected benefit $\left(E\left[\pi_{S 2}\left(\eta_{I}^{I I I}\right)\right]\right)$ is 2,552 . Then we can see the possibility that the supplier satisfy the subcontractor's demand is $1-F_{Y}\left(\left(Q_{S 1}^{I I I}-\eta_{I}^{I I I}\right) / v\right)=0.62$. The supplier's capacity supply uncertainty is reduced compared with the one under the scattered circumstance.

Within the benefit sharing contract, the joined expected benefits of the subcontractor and the integrated service supplier $\left(E\left[\pi^{I I}{ }_{S 1 I}\left(p_{I}^{I I}, Q_{I}^{I I}\right)\right]\right)$ is 17,136 .

Since the optimal expected profits of both the subcontractor and the integrated service supplier are greater than the ones under the scattered circumstance, namely, $E\left[\pi_{S 1}{ }^{I I I}\left(p_{S 1}{ }^{I I I}\right)\right]>$ $E\left[\pi_{S 1}\left(p_{S 1}{ }^{*}\right)\right]$ and $E\left[\pi_{I}^{I I I}\left(p_{I}^{I I I}, Q_{I}^{I I I}\right)\right]>E\left[\pi_{I}\left(p_{I}{ }^{*}\right)\right]$ are true simultaneously, we get the range of the parameter of the benefit sharing contract as $0.627<\xi^{I I}<0.815$. If the parameter of the benefit sharing contract falls into that range, the subcontractor and the integrated service supplier will accept the coordination contract, but the exact value of the parameter depends on the positions and negotiating ability of both sides.

The parameter of the benefit sharing contract, on the premise of ensuring the coordination between the parameter of the benefit sharing contract, is able to distribute benefits in either way, and thus offer the flexibility for the subcontractor and the integrated service supplier when they are in different positions. In the specific range, the expected benefits of the subcontractor and the integrated service supplier vary as Fig. 3 shows.

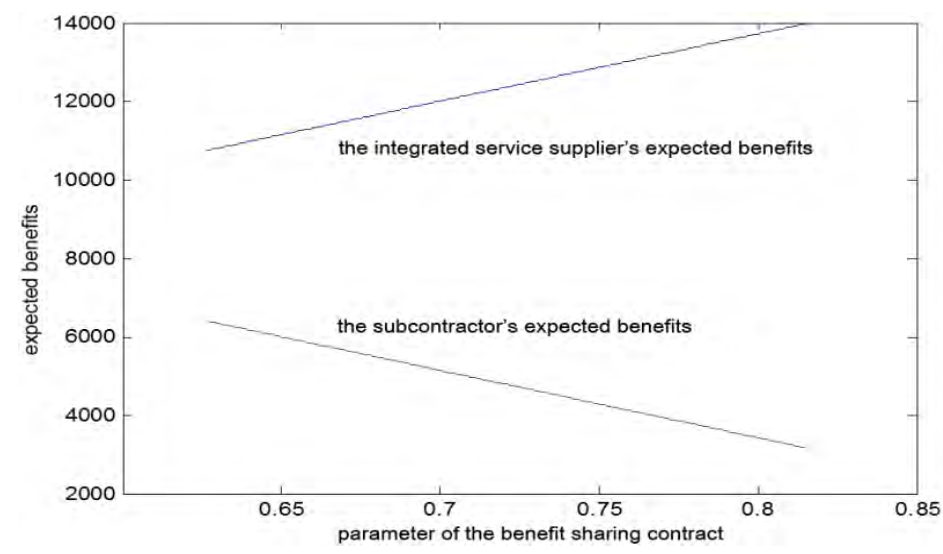

Figure 3: Relationship between revenue sharing and expected profit.

\section{CONCLUSIONS}

In consideration of the supply-demand uncertainty, this paper built the coordination model based on the reward-penalty sharing contract and discussed the capacity coordination of 
product service supply chain, aiming at increasing the whole benefits of the product service supply chain and those of all membership enterprises. It firstly analysed the decision behaviour of all membership enterprises in the product service supply chain under the scattered circumstance. The results showed that the possibility that the supplier cannot satisfy the subcontractor's subcontracting demand is irrelevant with the subcontracting quantity. Therefore, in the product service supply chain under the scattered circumstance, the supplier will not try to eliminate the supply uncertainty but leave it for the integrated service supplier.

Then, we analysed the three coordination models under different circumstances. Considering supply uncertainty, we built the supplier-subcontractor coordination model. It was found that when the subcontractor take penalty measures, the benefits brought by the increase of the subcontracting quantity $\left(Q_{S 1}\right)$ can make up the supplier's shortage loss, which encourages the supplier to accept the penalty-based coordination contract and raise its capacity supply. Considering demand uncertainty, we built the subcontractor-integrated service supplier coordination model based on the benefit sharing contract. The results showed that the integrated service supplier's order quantity, as well as the joined expected benefits of the subcontractor and the integrated service supplier will increase compared with those under the scattered circumstance. But the uncertainty that the supplier cannot satisfy the subcontracting demand keeps the same. Due to the lack of information sharing of the supplier's capacity supply, the optimal joined expected benefits of the subcontractor and the integrated service supplier is not sure to be realized. On the basis of the two models above, we built the product service supply chain coordination model based on the benefit-penalty sharing contract. In this coordination model, the supplier, the subcontractor and the integrated service supplier share information. The subcontractor take penalty measures to make the supplier reduce its service capacity supply uncertainty and shares benefit information with the integrated service supplier. It was found that the coordination based on the benefit-penalty sharing contract can lower capacity supply uncertainty and mitigate the impact brought by demand uncertainty, thus increasing the benefits of the whole product service supply chain and all membership enterprises.

\section{ACKNOWLEDGEMENT}

This work was supported by National Natural Science Funds of China (Grant No. 71301065), University Social Sciences and Humanities Funds of Jiangxi Province (Grant No. JC1309), Scientific and Technological Research Funds of Department of Education of Jiangxi Province (Grant No. GJJ14341).

\section{REFERENCES}

[1] Bhatnagar, R.; Chandra, P.; Goyal, S. K. (1993). Models for multi-plant coordination, European Journal of Operational Research, Vol. 67, No. 2, 141-160, doi:10.1016/0377-2217(93)90058-U

[2] Arshinder, S.; Kanda, A.; Deshmukh, S. G. (2008). Supply chain coordination: Perspective, empirical studies and research directions, International Journal of Production Economics, Vol. 115, No. 2, 316-335, doi:10.1016/j.ijpe.2008.05.011

[3] Cachon, G. P. (2002). Supply chain coordination with contracts, Working paper, Wharton School of Business, University of Pennsylvania, Philadelphia

[4] Chen, J. H.; Guo, F. L.; Shi, C. D. (2008). On supply chain revenue-sharing contract design under price-sensitive demand, Chinese Journal of Management Science, Vol. 16, No. 3, 78-83

[5] Chen, J. H.; Guo, F. L. (2010). Supply chain coordination with production capacity restriction and sale cost increasing under multiplicative demand, Operations Research and Management Science, Vol. 19, No. 5, 78-83 
[6] Thatcher, M. E. (2004). The impact of technology on product design, productivity, and profits: A duopoly model of price-quality competition, Proceeding of the $37^{\text {th }}$ Hawaii International Conference on System Sciences, 3389-3398, doi:10.1109/HICSS.2004.1265502

[7] Kraiselburd, S.; Narayanan, V. G.; Raman, A. (2004). Contracting in a supply chain with stochastic demand and substitute products, Production and Operations Management, Vol. 13, No. 1, 46-62, doi:10.1111/j.1937-5956.2004.tb00144.x

[8] Liu, L.; Tang, X. W. (2005). Study of the impact of lead time on service level decision, Control and Decision, Vol. 20, No. 11, 1265-1268

[9] Diao, X. J.; Yang, D. L.; Ren, Y. W. (2008). Competitive strategy of duopoly enterprise under uncertain consumer preference, Systems Engineering, Vol. 26, No. 8, 93-96

[10] Shen, C. L.; Zhang, X. X.; Qin, Z. Q. (2010). Supply chain contracts coordination with consumer's strategic returns policies under the service level constraint, Chinese Journal of Management Science, Vol. 18, No. 4, 56-64

[11] Shen, T. S.; Xiong, Z. K.; Wu, B. S. (2009). Pricing of product-supplementary services under duopoly manufacturers, Systems Engineering - Theory \& Practice, Vol. 29, No. 5, 37-43

[12] Shen, T. S.; Xiong, Z. K. (2010). Analysis of market competition on product-supplementary service by considering firm's commitment behavior, Chinese Journal of Management Science, Vol. 18, No. 4, 93-100

[13] Liu, W. H.; Ji, J. H.; Bao, X.; Gu, Q. L. (2008). Research on the two-echelon capacity cooperation coordination in logistics service supply chain, Journal of Wuhan University of Technology, Vol. 30, No. 2, 149-153

[14] Cui, A. P.; Liu, W. (2009). Study on capacity coordination in logistics service supply chain with options contract, Chinese Journal of Management Science, Vol. 17, No. 2, 59-65

[15] Lu, Y. B.; Lin, J. B.; Wang, B. (2010). Mobile service supply chain coordination with revenue sharing contracts, International Journal of Logistics Systems and Management, Vol. 6, No. 3, 267-278, doi:10.1504/IJLSM.2010.031981

[16] Yao, S. J.; Chen, J. H.; Zhang, X. R. (2011). Research on coordination countermeasures in product servitization supply chain based on service capacity, Soft Science, Vol. 25, No. 11, 56-60

[17] Tian, C.; Li, F.; Cao, R. Z.; Ding, W. (2008). Service capacity allocation and pricing, Network Operations and Management Symposium, 678-681, doi:10.1109/NOMS.2008.4575187

[18] Lee, K. S.; Ng, I. C. L. (2001). Advanced sale of service capacities: a theoretical analysis of the impact of price sensitivity on pricing and capacity allocations, Journal of Business Research, Vol. 54, No. 3, 219-225, doi:10.1016/S0148-2963(00)00119-3

[19] Ma, C. H. (2009). Study on collaboration of logistics service supply chain based on competence cooperation, China Business and Market, No. 2, 24-27

[20] Gao, Z. J.; Liu, W.; Wang, Y. F. (2009). Research to logistics service supply chain based on logistics capability, China Market, No. 23, 17-24

[21] Li, G.; Ma, S. H. (2009). Research on flexibility value of enterprise's logistics capability in decentralized supply chain, Journal of Management Sciences, Vol. 22, No. 2, 40-48

[22] Ma, S. H.; Meng, Q. X. (2005). Review of supply chain logistics capability researches, Computer Integrated Manufacturing Systems, Vol. 11, No. 3, 301-307

[23] Liu, W. H.; Ji, J. H.; Zhou, L. (2008). An order allocation model in two-echelon logistics service supply chain, Journal of Shanghai Jiaotong University, Vol. 42, No. 9, 1524-1528

[24] Wang, X. L.; Ma, S. H. (2011). Research on capacity coordination in a logistics service supply chain with demand and supply uncertainties, Operations Research and Management Science, Vol. 20, No. 2, 44-49

[25] Zhu, W. P.; Liu, W.; Gao, Z. J. (2012). Capability coordination in three-echelon logistics service supply chain, Journal of Shanghai Maritime University, Vol. 33, No. 2, 26-32

[26] Weng, Z. K. (1999). The power of coordinated decisions for short-life-cycle products in a manufacturing and distribution supply chain, IEE Transactions, Vol. 31, No. 11, 1037-1049, doi: $10.1080 / 07408179908969905$ 